\title{
CORRIGENDUM
}

\section{Spasticity may defend skeletal muscle size and composition after incomplete spinal cord injury}

AS Gorgey and GA Dudley

Spinal Cord (2008) 46, 825; doi:10.1038/sc.2008.142

Correction to: Spinal Cord (2008) 46, 96-102; doi:10.1038/ sj.sc.3102087; published online 17 July 2007

Since the publication of this article, the authors have realized that an error was made in the regression equation associated with Figure 3 . The constant value 85.38 was erroneously written as 0.52 .

The correct equation is therefore: skeletal muscle CSA $\left(\mathrm{cm}^{2}\right)=$ 10.418 (MAS) +85.38

The authors would like to apologize for this error. 